\title{
Electronic Health Record System
}

National Cancer Institute

\section{Source}

National Cancer Institute. Electronic Health Record System. NCI Thesaurus. Code C52657.

A computer-based clinical information system that is dedicated to collecting, storing, manipulating, and making available clinical information important to the delivery of patient care. The central focus of such systems is clinical data and not financial or billing information. 